\title{
Liver stores of vitamin $A$ in human fetuses in relation to gestational age, fetal size and maternal nutritional status
}

\author{
BY RAKSHA S. SHAH AND R. RAJALAKSHMI \\ Department of Biochemistry, Faculty of Science, M.S. University, Baroda-390002, India \\ AND R. V. BHATT, M. N. HAZRA, B. C. PATEL AND N. B. SWAMY \\ Obstetrics and Gynecology Department, S.S.G. Hospital, Baroda, India
}

AND T. V.PATEL

Kalpana Clinic, Baroda, India

(Received 11 July 1986 - Accepted 27 April 1987)

\footnotetext{
1. Studies were made on liver stores of retinol in aborted human fetuses and stillborn babies in relation to gestational age, fetal size and maternal retinol status. The mothers belonged to low- and high-income groups (LIG and HIG respectively) in urban Baroda.

2. Fetal weights were less than those reported by Widdowson (1968) for similar gestational ages and the deficits were greater in LIG.

3. The combined mean values ( $\mu \mathrm{g} / 1$ ) for maternal serum retinol for all gestational ages were 193 for LIG and 261 for HIG. They were found to decline in late pregnancy in the former but not significantly in the latter.

4. Fetal liver retinol concentrations were much lower than those reported for healthy Thai subjects by Montreewasuwat \& Olson (1979) in early pregnancy but showed complete 'catch up' in late pregnancy for HIG and to a considerable extent for LIG.

5. Significant correlations were found between maternal serum retinol, fetal liver retinol and fetal growth.

6. These findings stress the importance of adequate vitamin A supplies during pregnancy to prevent vitamin A deficiency and intra-uterine growth retardation in the newborn.
}

The association of vitamin A deficiency with protein-energy malnutrition is well-known (Venkatachalam \& Gopalan, 1960; Mclaren et al. 1965; Pereira \& Begum, 1973) but variable. The vulnerability to vitamin A deficiency during malnutrition may be related to liver vitamin A stores acquired before the episode of severe malnutrition. In studies on malnourished children in Madurai the prevalence of eye lesions was found to vary with the interval between the cessation of breast-feeding and admission to hospital as reported by the mother (Ramakrishnan, 1982), suggesting the importance of liver stores acquired before weaning. Similar observations have been made in Indonesia (Tarwotjo et al. 1982). Dave (1980) suggested that maternal vitamin A status may influence fetal liver stores of the vitamin.

The present studies were designed to investigate variations in liver stores of vitamin A in the fetus in relation to the plane of maternal nutrition as well as maternal vitamin $\mathrm{A}$ status.

\section{MATERIALS AND METHODS}

The subjects were from both low (LIG)- and high (HIG)- income groups (eighty-nine and twenty-five respectively). The families of LIG included manual labourers and unskilled workers with an annual income per head of Rs. 1200-1500 or less, whereas the corresponding income for HIG families which were from the professional class was Rs. 3000 or more. The difference in economic status was associated with differences in dietary intake and nutritional status. Differences between the two groups in dietary intake of pregnant women have been documented by Rajalakshmi (1980). The typical diets consumed by 
pregnant women in LIG and HIG provided (/d) respectively: 6570 and $8450 \mathrm{~kJ}$ (1570 and $2020 \mathrm{kcal}), 38$ and $49 \mathrm{~g}$ protein, $400-500$ and $1290 \mathrm{mg}$ calcium, 375 and $477 \mu \mathrm{g}$ vitamin A from carotene, 15 and $165 \mu \mathrm{g}$ preformed vitamin $\mathrm{A}$.

Fetuses of less than 20-22 weeks of gestational age were largely derived by medical termination of pregnancy but included a few spontaneously aborted fetuses whose growth was comparable to those derived by medical termination. Those above $20-22$ weeks were mostly derived from spontaneous abortions and stillbirths. Analysis of information on spontaneous abortions suggested that the fetuses fell into two distinct categories, namely, fetuses with extremely unsatisfactory development and those with reasonably satisfactory development, suggesting a possible difference in the cause of abortion, i.e. poor development and consequent rejection in the former case and sudden trauma in the latter case. Only those in the latter category were included in the study sample.

The fetuses were placed in ice as soon as they were aborted, transported to the laboratory and kept in the frozen state before dissection and analysis. For the assessment of gestational age, the mother was questioned about the last menstrual date with the help of a local calendar, and if necessary using local events. Gestational age was taken as menstrual age minus 2 weeks to allow for ovulation. The subjects were usually able to recall this quite precisely. The mother's blood sample was collected within $6 \mathrm{~h}$ of abortion.

Vitamin A in fetal liver and maternal serum was determined by the method of Neeld \& Pearson (1963). Measurements were done in duplicate and found to be almost identical.

For assessment of mean differences between groups, Student's $t$ test was used. The relation between variables was assessed using Pearson correlation coefficient, its significance calculated by transformation to a $t$ statistic (Ferguson, 1976).

\section{RESULTS}

The values for fetal weight and liver weights for LIG and HIG are presented in Table 1. When the fetal weights were expressed as a percentage of expected weights for gestational age, using the norms of Widdowson (1968), the values for the two groups were comparable in early pregnancy, but some deceleration of growth rate during mid-pregnancy was observed with a reversal towards term.

There were significant differences between the two groups with regard to retinol levels in maternal serum and fetal liver (Table 2).

For LIG serum retinol values tended to decline with the progress of gestation and the mean values for subjects with a gestation period of less than and more than 24 weeks were respectively 204 (SE 6.4) and 158 (SE 9.5) $\mu \mathrm{g} / 1(P<0.001)$. There was no statistically significant difference for HIG, the corresponding values being 263 (SE 17.5) and 237 (SE 19.7) $\mu \mathrm{g} / 1$. The concentration and content of fetal liver retinol increased with gestational age in both groups. At all gestational ages the values for HIG were found to be significantly higher than those for LIG. The magnitude of the difference was greater when liver content of retinol rather than its concentration was considered, because of differences between the two groups with regard to fetal weight and liver weight.

When the values for total liver retinol were calculated as a percentage of those at term, there appeared to be a much slower acquisition of retinol for LIG. A similar pattern is suggested when the values for each gestational period are considered as percentages of those found in healthy young Thai women by Montreewasuwat \& Olson (1979) (Table 3). That the differences in fetal liver retinol were related to maternal serum levels at different stages of pregnancy is suggested by the values shown in Table 4 . In both groups, higher concentrations of maternal serum retinol were associated with greater liver retinol stores in the fetus. Moreover, it is interesting that even for comparable ranges of maternal serum 
Liver stores of vitamin $A$ in human fetuses

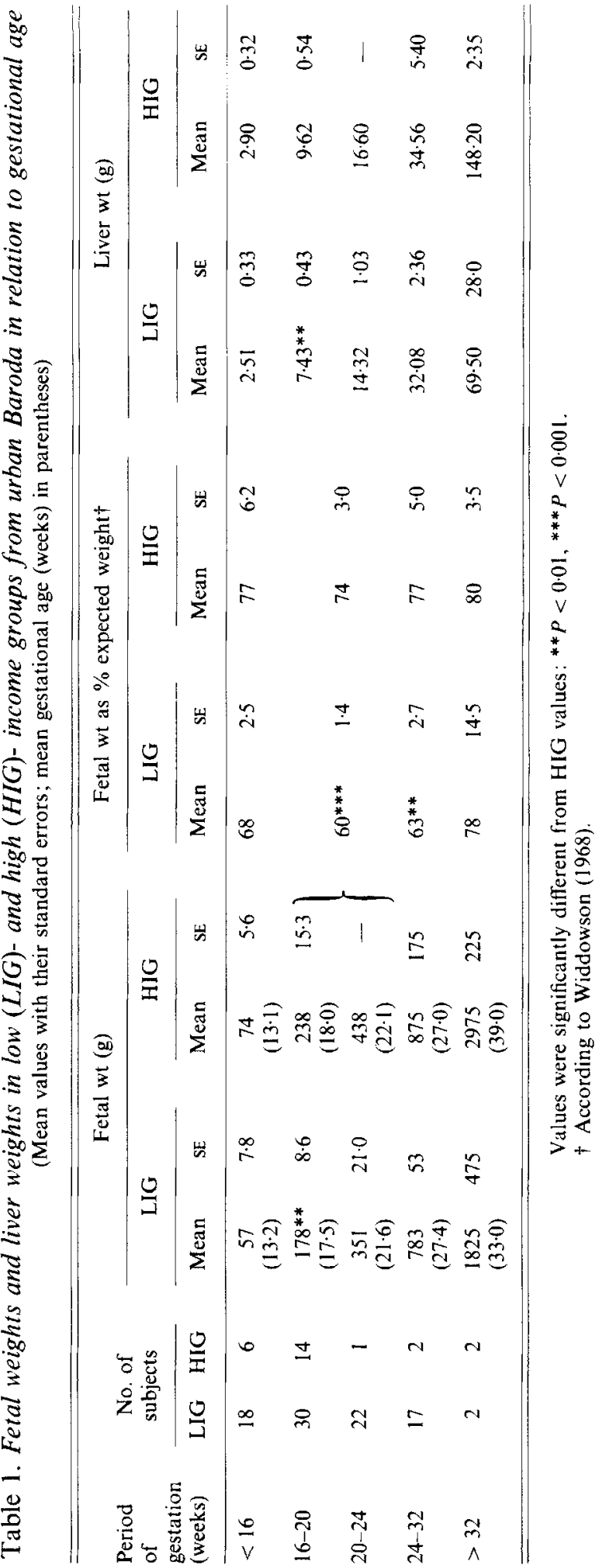




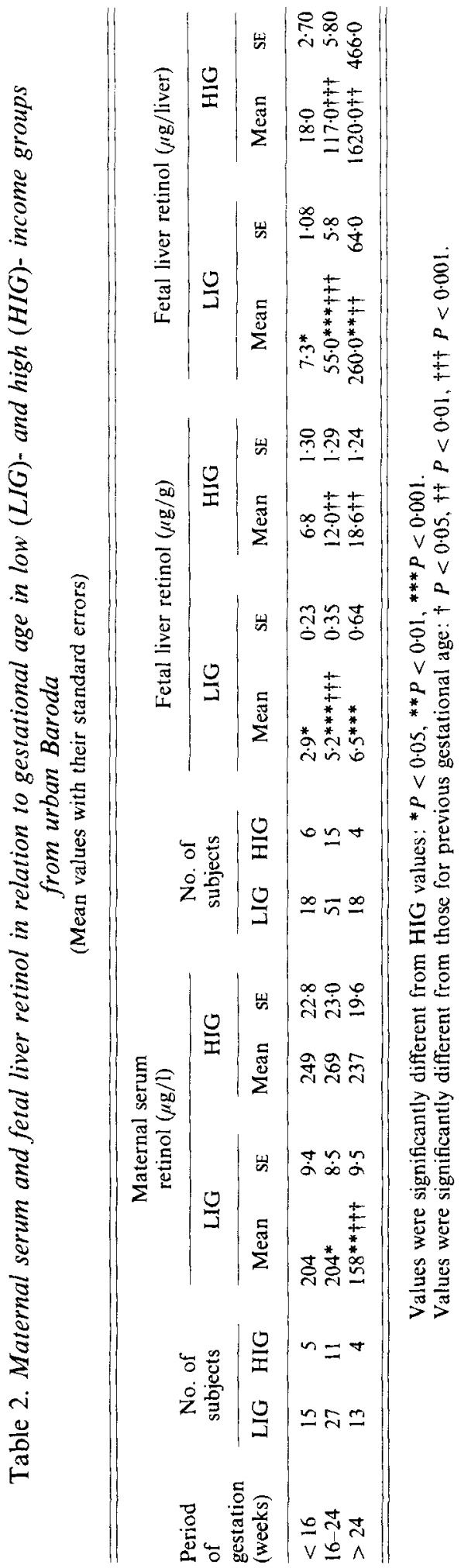


Table 3. Comparative values for fetal liver retinol stores in relation to gestational age in low (LIG)- and high (HIG)- income groups from urban Baroda

(Mean values with their standard errors, expressed as a percentage of norm given by Montreewasuwat \& Olson, 1979)

\begin{tabular}{|c|c|c|c|c|c|c|c|c|c|c|}
\hline \multirow{3}{*}{$\begin{array}{l}\text { Period } \\
\text { of } \\
\text { gestation } \\
\text { (weeks) }\end{array}$} & \multirow{2}{*}{\multicolumn{2}{|c|}{$\begin{array}{l}\text { No. of } \\
\text { subjects }\end{array}$}} & \multicolumn{4}{|c|}{ Concentration } & \multicolumn{4}{|c|}{ Content } \\
\hline & & & \multicolumn{2}{|c|}{ LIG } & \multicolumn{2}{|c|}{$\mathrm{HIG}$} & \multicolumn{2}{|c|}{ LIG } & \multicolumn{2}{|c|}{$\mathrm{HIG}$} \\
\hline & $\mathrm{LIG}$ & HIG & Mean & $\mathrm{SE}$ & Mean & $\mathrm{SE}$ & Mean & $\mathrm{SE}$ & Mean & $\mathrm{SE}$ \\
\hline$<16$ & 18 & 6 & $13 \cdot 7^{*}$ & 1.09 & $32 \cdot 0$ & 6.50 & $4 \cdot 5^{* *}$ & $0 \cdot 60$ & $9 \cdot 8$ & 1.50 \\
\hline $16-20$ & 30 & 14 & $26 \cdot 0 * * *$ & $2 \cdot 40$ & $65 \cdot 0$ & $9 \cdot 20$ & $10 \cdot 3^{* *}$ & $1 \cdot 00$ & $33 \cdot 0$ & 3.93 \\
\hline $20-24$ & 21 & 1 & $21 \cdot 0$ & $2 \cdot 24$ & $44 \cdot 0$ & & 13.7 & 1.62 & $35 \cdot 0$ & - \\
\hline $24-32$ & 16 & 2 & $31 \cdot 7$ & 4.45 & $98 \cdot 0$ & $36 \cdot 50$ & $17 \cdot 8^{* *}$ & 1.90 & $63 \cdot 0$ & 14.00 \\
\hline$>32$ & 2 & 2 & 81.0 & $12 \cdot 0$ & 99.5 & 0.50 & $65 \cdot 0$ & $31 \cdot 00$ & $100 \cdot 5$ & 1.50 \\
\hline
\end{tabular}

Values were significantly different from HIG values: ${ }^{*} P<0.02,{ }^{* *} P<0.01,{ }^{* * *} P<0.001$.

values, fetal liver stores of retinol for HIG were found to be higher than those for LIG. The product-moment correlations between maternal serum retinol and fetal liver retinol concentration in the two groups combined were 0.59 ( $n 58, P<0.01$ ) for gestational age less than 24 weeks and $0.83(n 17, P<0.001)$ for more than 24 weeks. The corresponding values for total liver retinol content were 0.32 and 0.70 . This association was much more clear-cut for LIG. The lower correlations for HIG are consistent with the absence of very low values in this group.

Since the two groups differed not only with regard to vitamin A status but also with regard to fetal weight, the values for liver retinol and fetal growth were analysed as shown in Table 5. Fetal growth was assessed by expressing fetal weights as a percentage of expected weight according to Widdowson (1968). A significant association was found between fetal growth and liver retinol concentration.

\section{DISCUSSION}

The fetal weights were less than those reported in the West and in Thailand for corresponding gestational age (Widdowson, 1968; Montreewasuwat \& Olson, 1979) but the values for 12-16 and 16-20 weeks compare to those reported by Abramovich (1969) and Lakshminarayana et al. (1974) respectively. The deficits in fetal weight as compared with the norms of Widdowson (1968) were consistent with differences in birth weights (Thomson \& Hytten, 1966; Rajalakshmi, 1971). The income-group differences were in accord with the higher proportion of small-for-gestational age infants among the poor (Achar \& Yankauer, 1962; Udani, 1963; Rajalakshmi, 1971). The deceleration of fetal growth for LIG during mid-pregnancy is consistent with the findings of Bhatt (1982).

The decline in serum retinol levels in late pregnancy, especially for LIG, is consistent with the findings in previous longitudinal studies of this laboratory (Rajalakshmi \& Ramakrishnan, 1969; Dave, 1980) and studies carried out elsewhere (Darby et al. 1953; Venkatachalam et al. 1962; McGanity et al. 1963). In the study of Cayer, Crescenzo and Cody reviewed by Moore (1957), the decline in maternal serum retinol levels towards term was followed by a post-partum rise. This was also found in our studies as the post-partum values of 218 (SE 5.9) and 293 (SE 8.0) $\mu \mathrm{g} / 1$ for LIG and HIG respectively (Shah \& Rajalakshmi, 1984) were greater than the late pregnancy values for 156 (SE 9.5) and 237 


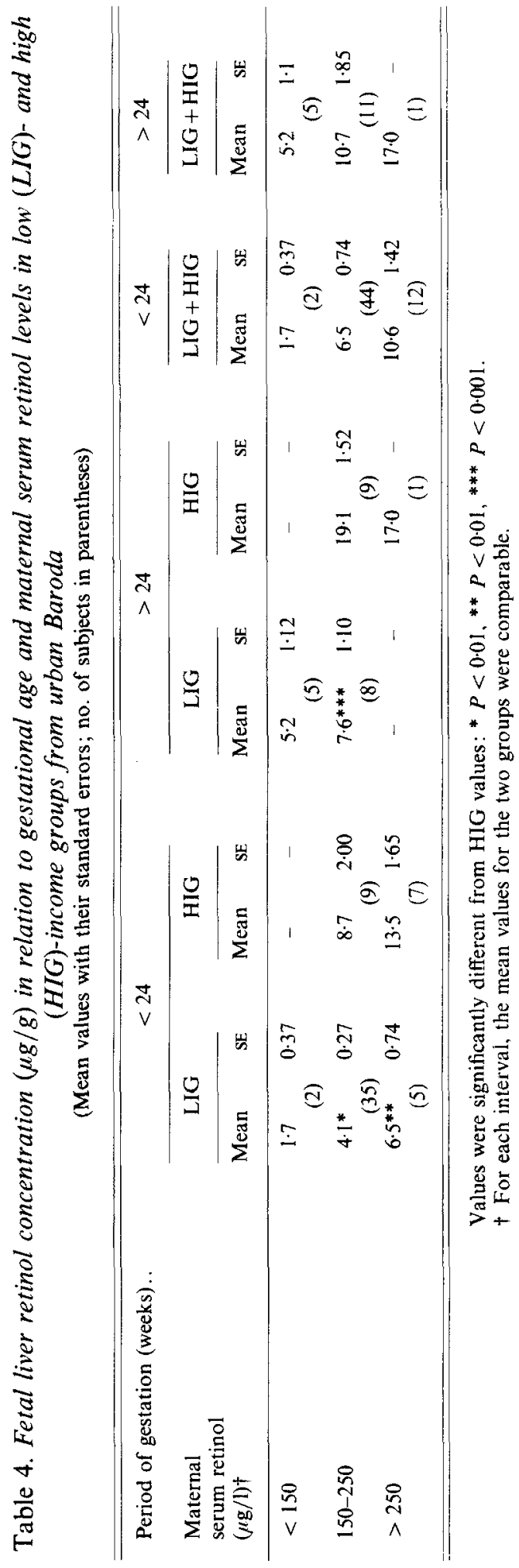


Table 5. Retinol stores in fetal liver $(\mu \mathrm{g} / \mathrm{g})$ in relation to fetal size and gestational age in low (LIG)- and high (HIG)-income groups from urban Baroda

(Mean values with their standard errors; no. of subjects in parentheses)

\begin{tabular}{|c|c|c|c|c|c|c|c|c|}
\hline \multirow{2}{*}{\multicolumn{2}{|c|}{$\begin{array}{l}\text { Period of gestation (weeks)... } \\
\text { Wt. as percentage of } \\
\text { Group } \quad \text { expected weight } t\end{array}$}} & \multicolumn{3}{|c|}{$<20$} & \multicolumn{4}{|c|}{$>20$} \\
\hline & & \multicolumn{2}{|c|}{ Mean } & SE & \multicolumn{3}{|c|}{ Mean } & $\mathrm{SE}$ \\
\hline \multirow[t]{2}{*}{ LIG } & $<60$ & \multicolumn{2}{|c|}{$4 \cdot 4$} & (16) & \multicolumn{3}{|c|}{5.4} & (23) \\
\hline & $>60$ & \multicolumn{3}{|c|}{$\begin{array}{r}4 \cdot 1 * *+\dagger \dagger \\
(32)\end{array}$} & \multicolumn{3}{|c|}{$7 \cdot 1^{* *}$} & 0.69 \\
\hline \multirow[t]{7}{*}{ HIG } & $>60$ & & $1+\dagger$ & 0.97 & & 16 & & 1.74 \\
\hline & & \multicolumn{7}{|c|}{$\begin{array}{l}\text { Product-moment ( } r \text { ) between fetal wt. as percentage of } \\
\text { expected wt. and fetal retinol liver concentration }\end{array}$} \\
\hline & & \multicolumn{5}{|c|}{$\begin{array}{c}\text { Statistical } \\
\text { significance: }\end{array}$} & \multicolumn{2}{|r|}{$\begin{array}{c}\text { Statistical } \\
\text { significance: }\end{array}$} \\
\hline & & $r$ & $n$ & $P$ & $r$ & $n$ & $P$ & $P$ \\
\hline & LIG & 0.65 & 48 & $<0.001$ & & 0.23 & 39 & NS \\
\hline & HIG & 0.39 & 20 & $<0.02$ & & 0.51 & 6 & NS \\
\hline & $\mathrm{LIG}+\mathrm{HIG}$ & 0.46 & 68 & $<0.001$ & & 0.46 & 45 & $<0.01$ \\
\hline
\end{tabular}

NS, not significant.

Values were significantly different from HIG values: ** $P<0.01,{ }^{* * *} P<0.001$.

Values were significantly different from values at $>20$ weeks of gestation: $\dagger+P<0.01,+\dagger \dagger P<0.001$.

$\ddagger$ According to Widdowson (1968).

(SE 19.6). However, Gal \& Parkinson (1974) reported an increase in serum retinol concentration during pregnancy. The conflicting findings in this regard have been reviewed by the National Research Council/National Academy of Science (1978).

The values for both maternal serum (Venkatachalam et al. 1962) and fetal liver retinol (Moore, 1957; Iyengar \& Apte, 1972; Gebre-Medhin \& Vahlquist, 1984) compare to those reported in the literature for similar groups. This is also true of the appreciable variability in fetal liver retinol and its increase with gestational age. A decrease in liver retinol with gestational age has been suggested by some studies on the liver retinol of premature and full-term infants (Woo \& Chu, 1939; Skurnik et al. 1944) but a similar marked decline was not found in the study by Montreewasuwat \& Olson (1979). In a recent study by GebreMedhin \& Vahlquist (1984), significant differences were found with regard to liver retinol stores between well-nourished fetuses from Sweden and poorly nourished fetuses from Ethiopia. Also, an increase in liver retinol concentration was found with the progress. of gestation in the Swedish fetuses whereas such a trend was not evident in Ethiopian fetuses. The finding is consistent with the slower and smaller increase in the vitamin in LIG fetuses and the sharp increase in the HIG fetuses of the present study.

The income group differences with regard to fetal liver retinol concentration suggest that maternal nutritional status had a significant influence on transfer to the fetus, although the amount of retinol accretion was small in comparison with dietary intakes not only for HIG (642 $\mu \mathrm{g}$ retinol equivalents) of carotene and preformed vitamin $\mathrm{A}$, but also for LIG (390 $\mu \mathrm{g}$ retinol equivalents). These differences may be associated with differences in retinolbinding protein levels. 
The differences in accretion of liver retinol suggest that the preterm infant of LIG may be more vulnerable to vitamin A deficiency if postnatal nutrition is unsatisfactory.

The observation that even for comparable maternal serum levels of retinol significant differences were found between LIG and HIG with regard to fetal liver retinol, suggests the possible involvement of other factors.

As fetal liver retinol stores seem to be influenced by fetal growth status as well as maternal retinol levels, the infant of LIG is in double jeopardy in that both fetal growth retardation and poor stores of retinol in the liver are more likely in this group.

In parallel studies on the vitamin A status of the newborn in relation to gestational age, size-for-age and maternal vitamin A status, we have found serum retinol levels to be significantly less in the mothers of small-for-gestational-age infants and premature infants compared with those of normal full-term infants, the values $(\mu \mathrm{g} / 1)$ for the three groups being respectively 178, 160 and 238 among the poor. Cord serum values also showed a similar pattern, the mean values for retinol $(\mu \mathrm{g} / \mathrm{l})$ being 108, 75 and 145 (Shah \& Rajalakshmi, 1984).

In conclusion, liver stores of retinol in human fetuses were found to increase with the progress of gestation and to vary with maternal retinol levels. Also, the influence of maternal status was greater in later pregnancy than in the earlier stages. Supplementation after mid-pregnancy at physiological levels can improve fetal stores without posing the risk of teratogenic effects or affecting adversely maternal metabolism. Such supplementation can also help to raise milk levels and promote the acquisition of vitamin A stores after birth.

This work was carried out with funds provided by the UGC to Professor R. Rajalakshmi for the project Fetal Development in relation to maternal nutrition. R.S.S. was in receipt of a CSIR fellowship.

\section{REFERENCES}

Abramovich, D. R. (1969). Journal of Obstetrics and Gynecology of the British Commonwealth 76, 523-526.

Achar, S. T. \& Yankauer, A. (1962). Indian Journal of Child Health 11, 157-167.

Bhatt, R. V. (1982). Baroda Journal of Nutrition 9, 52-54.

Darby, W. J., McGanity, W. J., Martin, M. P., Bridgforth, E., Densen, P. M., Kaser, M. M., Ogle, P. J., Newbill, J. A., Stockwell, A., Ferguson, M. E., Touster, O., McClellan, G. S., Williams, C. \& Cannon, R. O. (1953). Journal of Nutrition 51, 565-597.

Dave, I. (1980). Nutritional status during pregnancy and lactation. PhD Thesis, M.S.University, Baroda, India.

Ferguson, G. A. (1976). Statistical Analysis in Psychology and Education, 4th ed. Tokyo: McGraw-Hill, Kogakusha Ltd.

Gal, I. \& Parkinson, C. E. (1974). American Journal of Clinical Nutrition 27, 688-695.

Gebre-Medhin, M. \& Vahlquist, A. (1984). Acta Paediatrica Scandinavica 73, 333-340.

Iyengar, L. R. \& Apte, S. V. (1972). British Journal of Nutrition 27, 313-317.

Lakshminarayana, P., Nagaswamy, S. \& Balagopala, R. V. (1974). Indian Pediatrics 3, 803-810.

McGanity, W. J, Little, H. M., Fogeiman, A., Jennings, L., Calhoun, E. \& Dawson, E. B. (1963). American Journal of Obstetrics and Gynecology 103, 773-778.

Mclaren, D. S., Shirajian, E., Tchalian, M. \& Khoury, G. (1965). American Journal of Clinical Nutrition 17, 117-130.

Montreewasuwat, N. \& Olson, J. A. (1979). American Journal of Clinical Nutrition 32, 601-606.

Moore, T. (1957). Vitamin A. Amsterdam: Elsevier,

National Research Council/National Academy of Science (1978). Laboratory Indices of Nutritional Status in Pregnancy. Washington, DC: National Research Council/National Academy of Science.

Neeld, J. B. \& Pearson, W. N. (1963). Journal of Nutrition 79, 454-462.

Pereira, S. M. \& Begum, A. (1973). World Review of Nutrition and Dietetics 19, 2-50.

Rajalakshmi, R. (1971). Tropical Geographic Medicine 23, 117-125.

Rajalakshmi, R. (1980). In Maternal Nutrition During Pregnancy and Lactation, Nestlé Foundation Publication Series, pp. 184-203 [H. Aebi and R. Whitehead, editors]. Bern : Hans Huber Publishing Co. 
Rajalakshmi, R. \& Ramakrishnan, C. V. (1969). Gestation and Lactation Performance in Relation to Nutritional Status. Terminal Report of PL 480 Research Project FG-In-224. Baroda, India: Biochemistry Department, M.S. University.

Ramakrishnan, C. V. (1982). Studies on Marasmus and Kwashiorkor Children in Madurai and Trivandrum. Terminal Report. Baroda, India: Biochemistry Department, M.S. University.

Shah, R. S. \& Rajalakshmi, R. (1984). American Journal of Clinical Nutrition 40, 794-800.

Skurnik, L., Heikel, H. \& Westerberg, T. U. (1944). Zeitschrift für Vitaminforschung 15, 68-76.

Tarwotjo, I., Sommer, A., Soegiharto, T., Susanto, D. \& Muhilal, H. (1982). American Journal of Clinical Nutrition 35, 574-581.

Thomson, A. M. \& Hytten, F. E. (1966). In Nutrition, vol. 3, pp. 104-143. [G. H. Beaton and E. W. McHenry, editors]. New York: Academic Press.

Udani, P. M. (1963). Indian Journal of Child Health 12, 593-611.

Venkatachalam, P. S., Belavady, B. \& Gopalan, C. (1962). Journal of Pediatrics 61, 262-268.

Venkatachalam, P. S. \& Gopalan, C. (1960). Indian Journal of Medical Research 48, 645-653.

Widdowson, E. M. (1968). In Biology of Gestation vol. 2, The Fetus and the Neonate, pp. 1-49 [N.S. Assali, editor]. New York: Academic Press.

Woo, T. T. \& Chu, F. T. (1939). Chinese Journal of Physiology 15, 83-99. 